\title{
MULTI BAND INSAR ANALYSIS OF SUBSIDENCE DEVELOPMENT BASED ON THE LONG PERIOD TIME SERIES
}

\author{
F. C. Çomut ${ }^{\mathrm{a}}$, A. Ustun ${ }^{\mathrm{b}}, \mathrm{M}$. Lazecky $^{\mathrm{c}}$, M. M. Aref ${ }^{\mathrm{d}}$ \\ a Turkey Disaster \& Emergency Directorate (AFAD) of Denizli, Denizli, Turkey, - fatma.c.comut@afad.gov.tr \\ ${ }^{\mathrm{b}}$ Department of Geomatics Engineering, Kocaeli University, Kocaeli, Turkey - aydin.ustun@kocaeli.edu.tr \\ c IT4Innovations, VSB-TU Ostrava, Czech Republic-milan.lazecky@vsb.cz \\ ${ }^{d}$ Department of Geomatics Engineering, Istanbul Technical University, Istanbul, Turkey - mohseni.aref@gmail.com
}

KEY WORDS: InSAR, Konya closed basin, subsidence, GIS

\begin{abstract}
:
The SAR Interferometry (InSAR) application has shown great potential in monitoring of land terrain changes and in detection of land deformations such as subsidence. Longer time analysis can lead to understand longer trends and changes. Using different bands of SAR satellite (C- from ERS 1-2 and Envisat, L- from ALOS) over the study area, we achieve knowledge of movements in long-term and evaluation of its dynamic changes within observed period of time. Results from InSAR processing fit with the position changes in vertical direction based on GPS network established over the basin as an effective geodetic network. Time series (StaMPS PS+SB) of several points over Çumra County in eastern part of Konya City show a general trend of the deformation that is expected to be approximately between -13 to $-17 \mathrm{~mm} /$ year. Northern part of Karaman is affected by faster subsidence, borders of the subsidence trough were identified from Envisat.

Presenting InSAR results together with GIS information about locations and time of occurrence of sudden subsidence, urban/industrial growth in time and climate changes helps in better understanding of the situation. This way, the impact of natural and man-made changes will be shown for urban planning thanks to InSAR and GIS comparisons with hydrogeological modeling. In this study we present results of differential and multitemporal InSAR series using different bands and GIS conjunction associated with seasonal and temporal groundwater level changes in Konya Closed Basin.
\end{abstract}




\section{INTRODUCTION}

Since the beginning of civilization, humans have used water and land for daily life as well as agricultural and development purposes. This has led to a subsidence problem in conjunction with the overuse of water and natural resources growing along with population increase rate. Moreover, when rapid rates of subsidence are seen in some coastal areas, city centers and agricultural areas, the problem is augmented by the increased risk of flooding, and extending the impact of large populations. Besides man made effects for land subsidence, natural subsidence can result from tectonic activity (subsidence/uplift, earthquake, etc.) and dewatering of sediments (dry periods and/or drop of sea level). Understanding the relative impact of subsidence is critical to know and estimate properly both natural and manmade effects.

Variety of geological and hydrological hazards caused by land subsidence challenge is difficult to predict. Because of this reason, it is important to monitor subsidence continuously. Problems of subsidence are generally associated with maintaining of major infrastructures and cause damage to inhabited areas.

Land subsidence due to ground-water overdraft in the Konya Closed Basin which is a big part of Anatolia/Turkey began in the mid-1970's. The historical first-order leveling records to the benchmarks of Turkish National Vertical Control Network (TNVCN) show significant relative displacements that point out about 20-50 cm subsidence during the period of 70s and 90s (Ustun et al., 2010). Depending on the decreasing water volume (see e.g. Göçmez and İşçioğlu, 2004), a deformation and compaction are observed on aquifer systems that hold the groundwater (Ustun et al., 2015). Moreover, for more than 40 years, the existence of some sinkhole hazards is known by the local people, especially by farmers. Bayari et al. (2009) and Ozdemir (2015) has investigated the formation and spatial characteristics of these sinkholes (Turkish name obruk) using GIS tools within the area. Starting from 2006, the space based geodetic techniques such as GPS and InSAR have been used to monitor the deformation caused especially by extraction of groundwater in the study area. Thanks to the characteristics of space-based techniques, such hazards over big areas can be determined easier than before. The purpose of this article is to review the status of subsidence occurrences in conjunction with groundwater-level trends in the Konya Closed Basin from 1992 to 2010 in order to define the extent and magnitude of subsidence (especially in Konya City Center) by means of multi-band InSAR analysis and to identify probable causes where practicable; and to propose a continuing surveillance program for monitoring areas of continuing or potential subsidence.

\section{STUDY AREA AND METHODOLOGY}

\subsection{Study Area}

Monitoring subsidence using InSAR method is very significant part of our study. We will work on Konya Closed Basin having a surface area of approximately $55000 \mathrm{~km}^{2}$ which is located in Central Anatolia Region of Turkey as the biggest closed basin involving Konya, Karaman, Nigde and Aksaray provinces (See Fig.1).

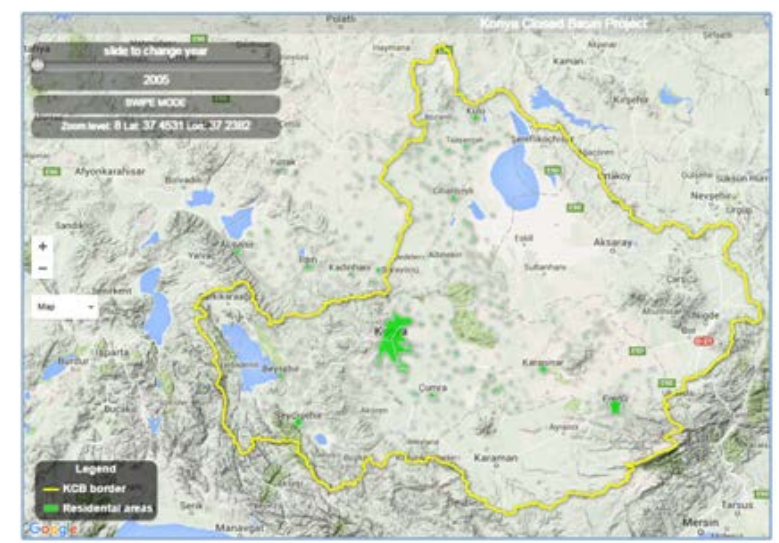

Figure 1. Study Area: Konya Closed Basin Border and Residential Areas

The study area of interest generally withstands on the steep slopes of Taurus mountains in the south that are mainly oriented towards the west and the basin is quite wide for performing a deformation monitoring. Its deformation characteristics is primarily caused by groundwater extraction. The problems coming from the decrease of groundwater are not limited to loss of water resources (Göçmez and İşçioğlu, 2004). The current study focusing on surface deformations is based on the geodetic techniques which have capable of detecting any compaction of aquifer systems.

\subsection{Data used within the scope of work}

An active subsidence observed since past 50 years around Konya county of Konya Closed Basin (Ustun et al., 2015) has been investigated by terrestrial and remote sensing methods including advanced InSAR techniques. The SAR processing history in the basin for the first time has begun by using the Envisat Asar images of European Space Agency over the Category-1 project, 5863. Later, the data pool has been enlarged with the involvement of additional images of ERS-2 and ALOS PALSAR. This has enabled that the project team considers the multi-band image processing for different surface characteristics since they present processing facility in urban and agricultural areas for the Konya and the surrounding countryside. For instance, the ALOS PALSAR images are extremely effective for the detection of agricultural areas so they have been deemed appropriate to be processed (Clewley et.al., 2015).

The descending transition of satellite position data mode is preferred to minimize the effect of geometric distortions which are foreshortening, shadow and layover. Hence, the track numbers, 114 (2002 November to 2010 June - 20 images), 343 (2003 June to 2010 April - 20 images) and 436 (2003 July to 2010 July - 15 images) in the descending mode have been selected from ASAR sensor (VV polarization IS mode 2) of Envisat satellite (C-band) which are totally 55 images. In case of 10 images from 3 different tracks (2006 September to 2008 February) of ALOS PALSAR operating on L-band, DInSAR analyses have been preferred for the agricultural areas. Their properties are FBS (Fine Mode Single Polarisation), $28 \mathrm{Mhz}, 10 \mathrm{~m}$ resolution, 64x66 km in size and $\mathrm{HH}$ polarization. And lastly 23 images from ERS-2 satellite (C-Band) gained from 114 track (1995 May to 2000 December). Figure 2 displays the frame extents of all these images based on the Google Earth view. 
The most important point that is considered in the image selection, is acquisition time of images (temporal baseline), and the relative position of satellite at the time of image capturing. Taking into consideration the rainfall period between October and May, dry season has been chosen for image selection to minimize atmospheric interference on phase observations. In addition, approximately 3 months difference between the consecutive dates of image acquisition has been selected so that the surface displacement in the study area may occur more than the length of radar wave. Therefore this makes possible to reveal more clearly the amount of deformation.

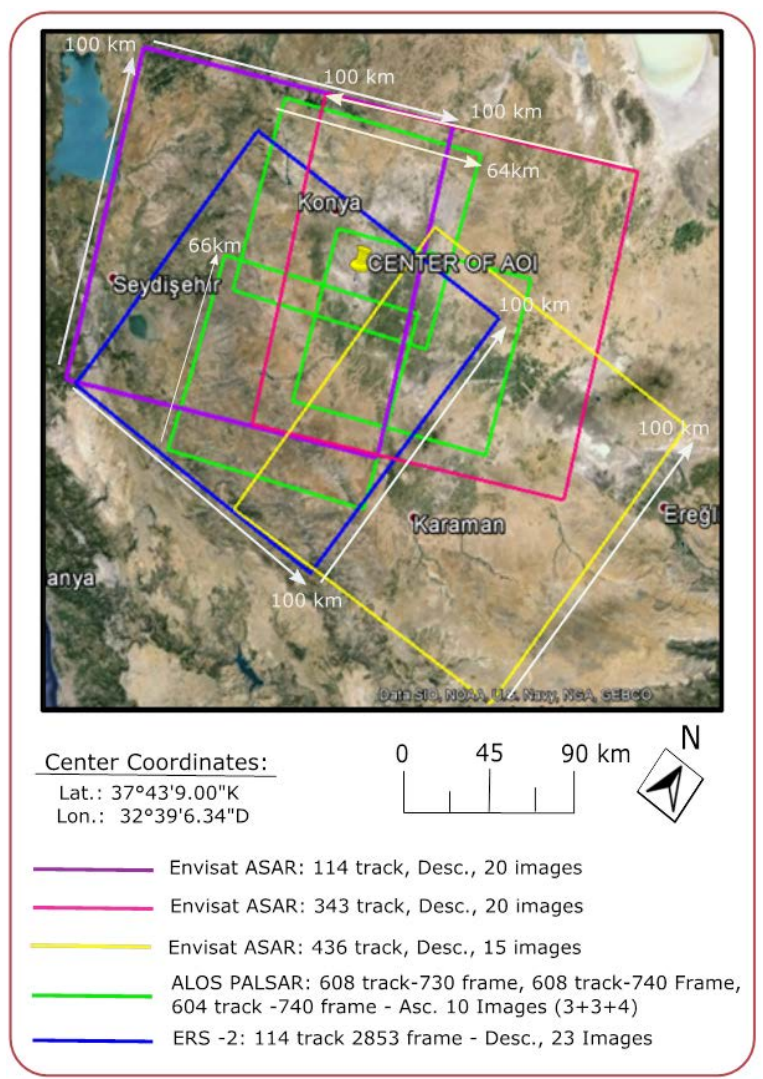

Figure 2. Envisat ASAR, ALOS PALSAR and ERS-2 SAR image frames on the Google Earth view

\subsection{Methods used for InSAR processing}

For this research we used mainly StaMPS (Hooper, 2008) for processing image pairs using PS and SB techniques. The same data have been reprocessed using Sarproz (Perissin et. al., 2011) implementation of PS InSAR or original Quasi PSInSAR approach. Both software packages yield similar results with Sarproz offering an additional sight in the sense of advanced post-processing techniques for visualisation and focusing on a small area. While it is relatively simple task to evaluate movements over urbanized areas using PS InSAR with current implementations, the non-urbanized (rural) areas have to be assessed by StaMPS SB or Sarproz Quasi PS techniques in order to extract information from stacks of data that are far from being optimal for precise evaluation of terrain deformations.
Due to the limited data availability, ALOS PALSAR images over the area were used only for DInSAR analysis which means a simple phase difference between two SAR images with basic corrections for orbital effects, topography based on DEM reduction and similar. For detection of subsidence troughs this is often sufficient.

\section{PROCESSING RESULTS}

According to the land use characteristics, we separate our study area into the three different sections in which we observed a certain part by GNSS. This article has InSAR time series results for some points that are detected in both ERS-2 and Envisat ASAR results. And also it includes DInSAR results of ALOS PALSAR especially for agricultural areas.

\subsection{Envisat ASAR Results}

The interferograms of 114 and 343 tracks that mainly cover large industrial area within Karatay County in the west and southern agricultural area of Çumra County are generated from SarProz and StaMPS, see Fig. 3 and Fig. 4, respectively. The subsiding area is seen as red to yellow parts in the left and right panels of Figure 4 where the scale is from -20.6 (red) to 6.6 (blue) mm/year for results form both tracks 114 and 343. The Sarproz estimated deformation rates in Figure 3 correspond to -30 (red) to +30 (blue) $\mathrm{mm} /$ year w.r.t. reference (green) areas. It can be seen that the processing determines a subsidence trough over a large part of the county. Outlying pixels should be considered as noise.

Other areas have already been processed, for example Karaman city center was monitored for subsidence using Envisat ASAR track 436 in (Çomut et.al., 2014).

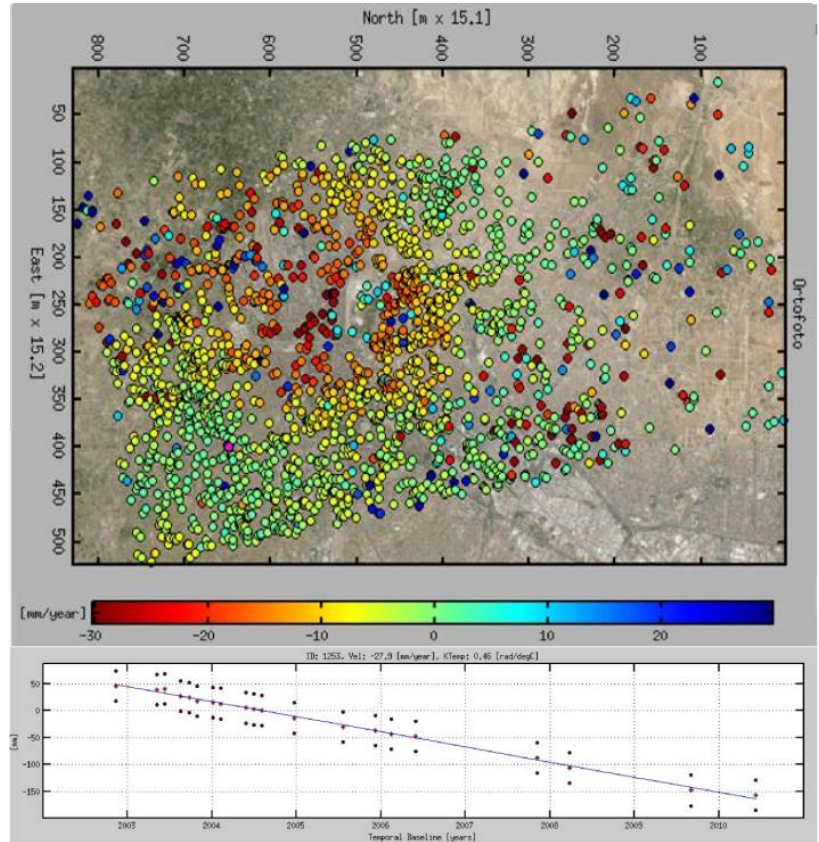

Figure 3. SarProz PS InSAR results for track 343 (Konya City Center - Karatay County) 


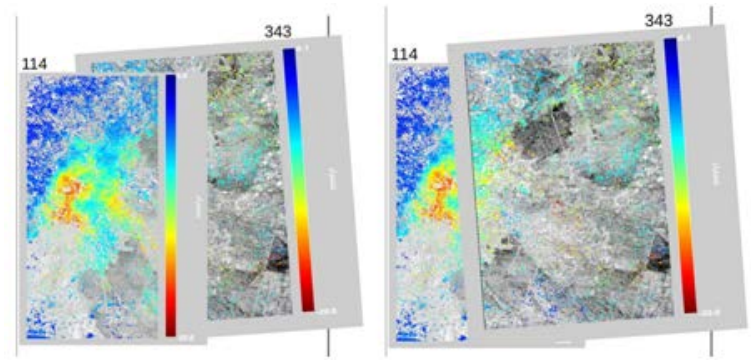

Figure 4. StaMPS PS InSAR results for tracks 343 and 114 (Çomut, et.al., 2015)

\subsection{ALOS PALSAR Results}

Though the number of ALOS PALSAR images was limited, its well penetrating L-band radar signal ensured high coherence even over most of agricultural areas and could detect subsidence troughs there as is visible at figures 5 and 6.

Deformation can be seen from Figure 5 over Konya City Center and also vegetated areas which Eastern part of Konya City (1 fringe - aprox. 8 rad.).

Almost the same results from shorterFigure 6 can be seen as Figure 5 not only Eastern part of Konya but also Eastern part of Kaşınhanı village (Local of Çarıklar Fatih) which is nearby FETH GPS point. Subsidence rates are almost the same with StaMPS PS InSAR results from ERS data (Shown in Figure 8).

In Figure 5 and Figure 6 the scale bar colour difference is because of combining master and slave images' coregistration order. In Figure 5 master image is after slave image and in Figure 6 master image is before slave image.

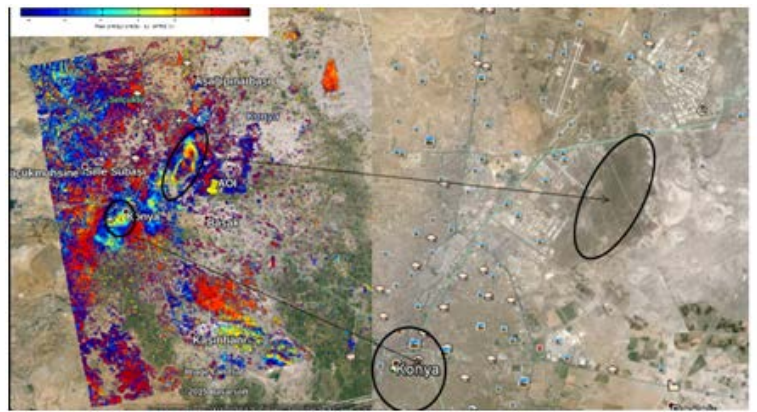

Figure 5. ALOS PALSAR DInSAR results from 608 track 740 frame (2008/02/12-2006/09/24 ifg - 480 days)

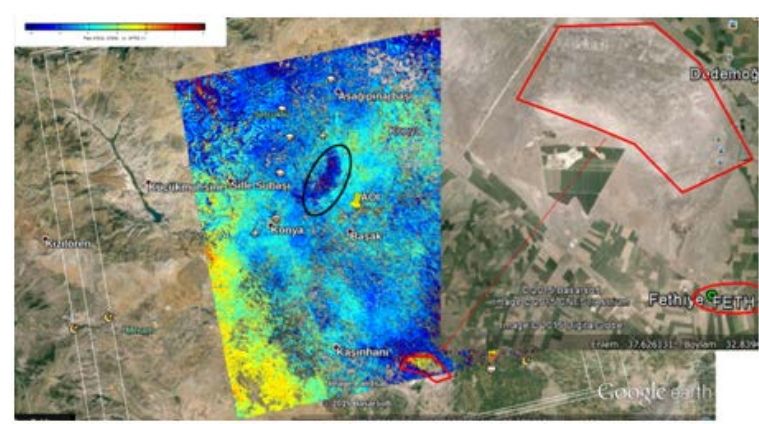

Figure 6. ALOS PALSAR DInSAR results from 608 track 740 frame (2006/06/24-2006/09/24 ifg- 93 days), FETH is GPS point

\subsection{ERS Results}

The same computing approach as used for Envisat data analysis has been applied also in case of ERS-1 and ERS-2 data. These data however don't overlap with the critical subsiding area, however results from southern part of Konya city show coherent subsidence pattern as within the following years, as observed by Envisat.

Following figures show examples of ERS InSAR monitoring over urban areas. It can be said that while urban areas show appropriate consistency that can be described as high coherence within the dataset, approaches of evaluation within non-urban areas and especially highly changing agricultural areas are purely experimental. A typical overview is demonstrated in Figure 7 here the same dataset over the same area is processed by different techniques that resulted in vastly different outcomes, depending on the pixels selected for the processing. In this figure, left image shows average spatial coherence within ERS interferograms, middle image is a result from PS processing using pixels containing stable and high intensity scatterers, right image is a result from coherence-weighted Quasi PS-InSAR method using less stable pixels. This figure demonstrates the need of appropriately selected pixels for processing. Unfortunately the agricultural areas are causing strong decorrelation of pixels in ERS interferograms and it is not possible to include them in processing neither to use their extracted information to perform comparison with GPS results because the GPS station weren't connected to any object such as building.
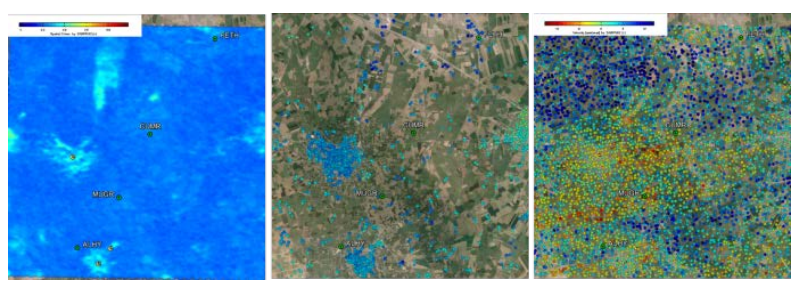

Figure 7. Average spatial coherence (left) and differences between processing approaches: PS InSAR (middle) and Quasi PS InSAR (right) over Cumra area from ERS data.

Right image is considered as wrong result due to large number of noisy pixels as input for the processing

Figure 8 shows an example of subsidence detected in nonurban area near Cariklar Fatih using StaMPS processing. StaMPS algorithms perform spatial phase unwrapping that may lead to smooth results but also can indicate false movements. This figure is an example of result that should be compared to ground truth before interpretation. Figure 9 on the other hand shows deformations in urban area referred to a nearby point. Urban structures have stable reflection in InSAR time series not affected by temporal decorrelation, therefore this information can be directly compared to instruments such as GPS stations. 


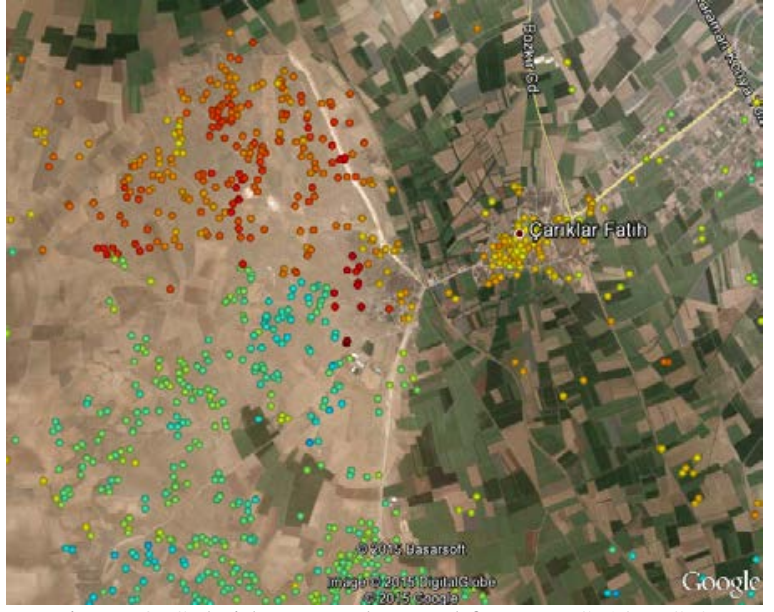

Figure 8. Subsidence as detected from ERS-1/ERS-2 satellites (1995-2000) in Cariklar Fatih and its surroundings (StaMPS). The scale is from -12 (red) to 5 (blue) mm/year

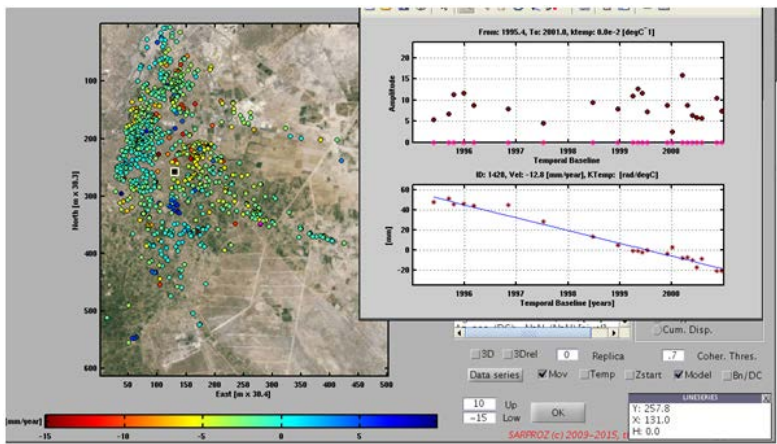

Figure 9. Evaluated movements over urbanized Konya area by ERS PS-InSAR using SarProz

\section{COMPARISON WITH GROUND TRUTH DATA}

\subsection{Comparison with GPS measurements}

There is a number of continuously measuring permanent GPS stations installed over the whole Konya closed basin area (see Figure 10). Comparison of InSAR results with GPS measurements for Ground Truth have already been done for one GPS point (KCKY) in (Çomut, et.al., 2015) - in this study, StaMPS results of Envisat dataset from November of 2002 and June of 2010 have been compared with interpolated GPS velocities results.

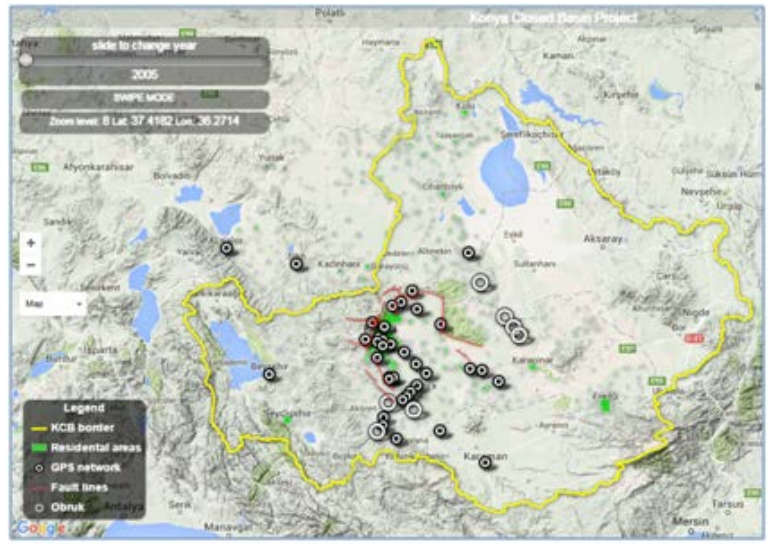

Figure 10. GPS network on study area with sinkholes and fault lines

BELD GPS point is the most subsiding point in our AOI and coordinate/subsidence rate from 2011 to 2015 is: 32.48647 (Long.), 37.87735 (Lat.), -22.45 (Subsidence rate (cm/yr)), 1.74 (SD) (Çomut, et.al.,2015) (See Figure 11 upper part). Lower part of Figure 11 depicts PS points of Envisat dataset in the close neighbourhood of BELD GPS station. It is possible to see that a subsidence is detected at these points. However the amount of subsidence is underrated within PS results. This is due to limitations of current Envisat dataset such expected rate of $\sim 20 \mathrm{~cm} /$ year cannot be properly evaluated from the data. This theoretical optimistically maximal detection limit vkrit should be possible to quantify using Eq. 1 where $\lambda$ is SAR wavelength, $B_{T}$ is the average temporal baseline (revisit time between SAR images). In the case of this Envisat track 114 dataset where $\lambda$ mean $B_{T}=105$ days (i.e. 0.2877 year), the theoretical estimable $v_{\text {krit }}=9.66$ $\mathrm{cm} /$ year.

(1)

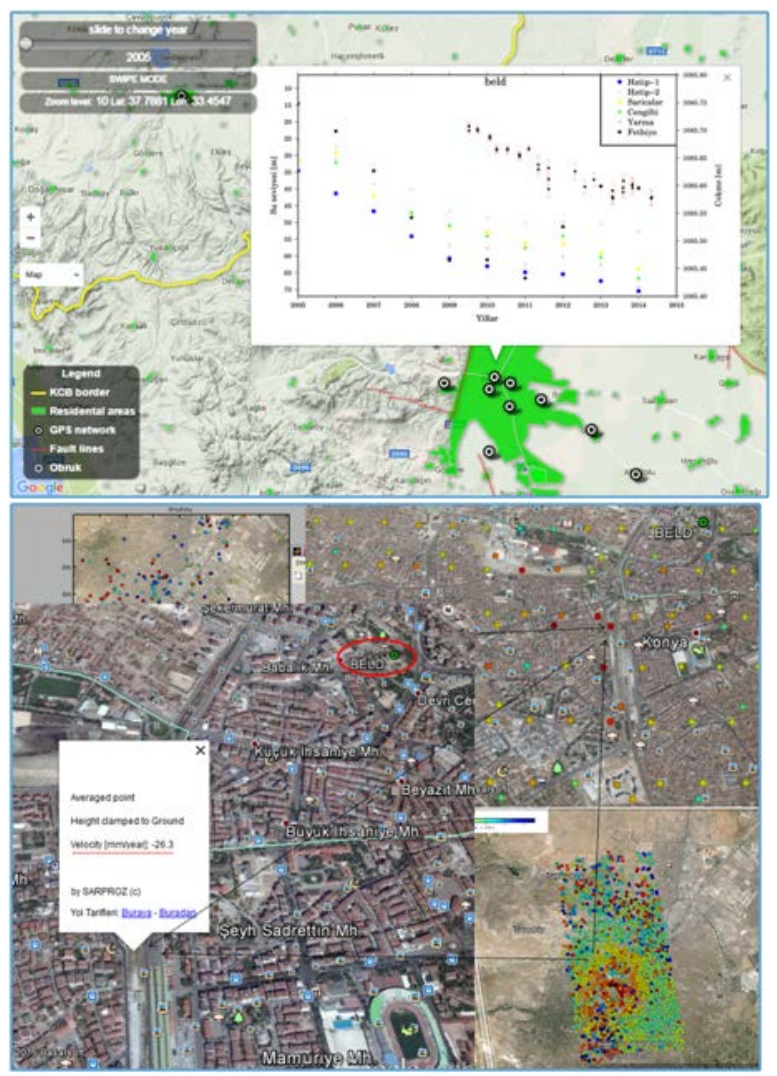

Figure 11. 343 track, 20 Envisat Descending images, SarProz PSI results, subsidence rate of PS over BELD GPS Station

\section{RELATION OF DETECTED CHANGES TO RAINFALL AVERAGE}

From the InSAR results and comparison with GPS results it is clearly seen that especially nearby the fault lines (See Figure 10) have shown deformations. From literature researches we know that this subsidence mostly caused by groundwater extraction and also depends on the rainfall 
average. For this reason we want to show the relation between rainfall average with observed subsidence over AOI.

From 12 meteorological stations over Konya Closed Basin the rainfall map (Figure 12) created and this map shows the critical importance of rainfall necessity over the Basin. The lowest rainfall value in Turkey is especially inner parts of the basin and also Karapınar Region and surroundings which includes many number of sinkholes.

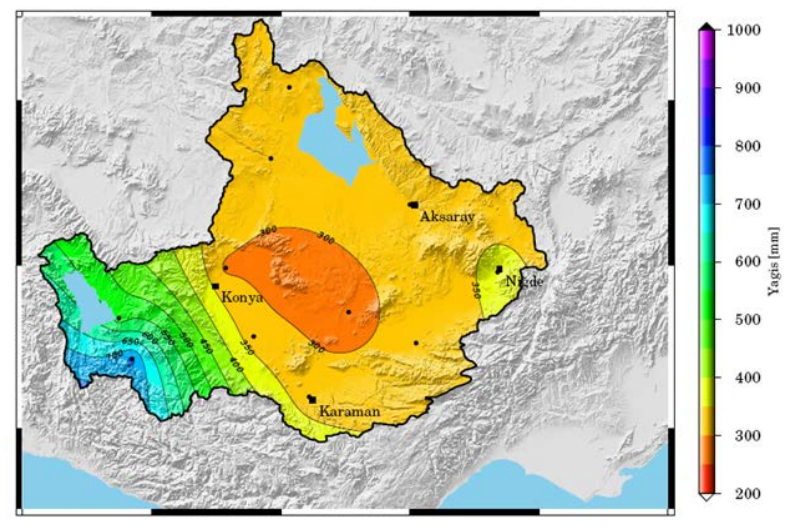

Figure 12. Average of annual rainfall data distribution from

12 meteorological stations over KCB (Ustun, et.al., 2015)

The overall area from track 114 as observed by StaMPS PS InSAR shows a similar spatial pattern of subsiding area as are these borders of heavy rainfall data - see Figure 13.

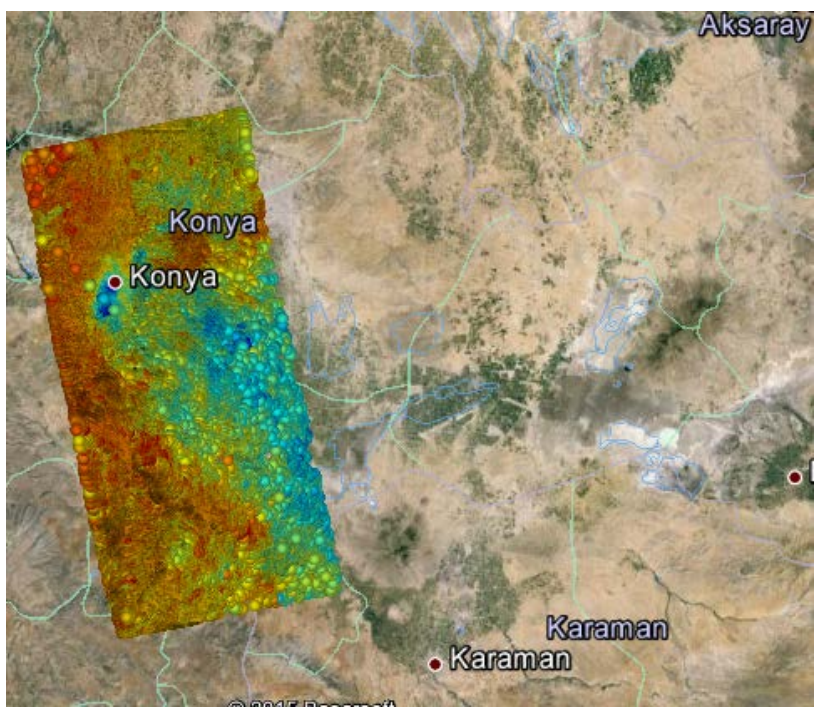

Figure 13. StaMPS PS InSAR of Envisat track 114, blue colour means subsidence of down to $25 \mathrm{~mm} /$ year, red colour would mean an uplift of less than $5 \mathrm{~cm} /$ year

\section{CONCLUSIONS}

We want to present results of a PS InSAR study in Konya Closed Basin that focuses to observe and to monitor development of land subsidence in time. We present a set of ground deformation maps that allow for a greater resolution in displacement time series than previously available through the use of conventional InSAR. Examining determined deformation dispersion and qualification (scale) of the region is aimed. Envisat, ALOS and ERS images used to achieve deformation maps.
SAR data of AOI evaluated using PSInSAR processing or/and other multitemporal technique such as Quasi PS InSAR, SBAS/SB or similar method, based on Sarproz and StaMPS software packages abilities. The processing results detected movements of subsidence in Konya however especially in agricultural areas the subsidence values have been evaluated wrongly or not at all due to fast decorrelation.

GPS stations placed in agricultural fields in Cumra region couldn't be properly compared, as stated in previous section. An approach was performed for case of Envisat dataset where a reference point was selected near to FETH station in Fethiye village. The closest GPS station CUMR was in $5 \mathrm{~km}$ distance. Density of PS points between both far stations was very low to capture any reliability in estimated movements. Moreover, except of FETH, the GPS stations were placed directly into the agricultural field without any stable object in their close neighbourhood. As a conclusion, it was not possible to reliably estimate movements in non-urban areas based on available ERS/Envisat images using PS InSAR neither other available techniques.

The main objective of the research was to evaluate if the InSAR method can be applied to provide an early warning in advance of local dangerous deformations, i.e. if the accelerated deformation changes can be detected confidently using current satellite SAR systems. We expect to perform this evaluation by our further work, either using highresolution high-number of X-band data or applying a continuous monitoring using Sentinel-1 images that offer very short temporal baseline and very large image extent. Also it should be possible to apply Alos-2 images for detection of long term subisdence movements in the area with the advantage of penetrating L-band wave.

\section{ACKNOWLEDGEMENTS}

The work in the paper was supported by the TUBITAK in Turkey (Contract No.110Y121, Project Name: Monitoring of land subsidence in Konya Closed Basin using geodetic methods and investigate its causes) and was supported by the European Regional Development Fund in the IT4Innovations Centre of Excellence project (CZ.1.05/1.1.00/02.0070). Access to computing and storage facilities owned by parties and projects contributing to the National Grid Infrastructure MetaCentrum, provided under the programme "Projects of Large Infrastructure for Research, Development, and Innovations" (LM2010005), is greatly appreciated.

Climate and hydrogeological characteristics for KCB were taken from final report of project of TUBITAK (The Scientific and Technological Research Council of Turkey) under Grant Number 110Y121. (Ustun, et.al., 2015)

The authors are very thankful to ESA for the SAR data (provided under ESA Category-1 project, contract No.C1P5863). The authors would also thank Dr. Daniele Perissin for providing the SarProz Software for testing to us and Prof. Andy Hooper for providing the StaMPS Software package freely for researchers.

\section{REFERENCES}

Bayari, C. S., Pekkan, E., Ozyurt, N. N., 2009. "Obruks, as giant collapse dolines caused by hypogenic karstification in 
central Anatolia, Turkey: Analysis of likely formation processes”, Hydrogeology Journal, 17 (2), 327-345.

Clewley, D., Whitcomb, J.,Moghaddam, M., McDonald, K., Chapman, K., and Bunting, P., 2015. "Evaluation of ALOS PALSAR Data for High-Resolution Mapping of Vegetated Wetlands in Alaska”, Remote Sens., 7(6), 7272-7297; doi:10.3390/rs70607272

Çomut F. C., Lazecký, M., Perissin, D., Ustun, A., 2014. Monitoring of Land Subsidence in Konya Closed Basin between 2003-2010 by means of PS InSAR processing: first results in Karaman District. In: CENTERIS 2014, 15-17 Oct 2014, Troia, Portugal.

Çomut F. C., Lazecky M., Ustun A. , Yalvac, S., 2015. Land Subsidence Detection in Agricultural Areas of Konya Closed Basin By Ps-InSAR And GNSS Observations, FRINGE 2015 Workshop, ESRIN, Frascati - Italy, 23-27 March 2015.

Göçmez, G, İşcioğlu A., 2004. Konya Kapalı Havzası'nda yeraltı suyu seviye değişimleri, Yeraltısuları Ulusal Sempozyumu, S.9-19.

Hooper, A., 2008. "A Multi-Temporal InSAR Method Incorporating Both Persistent Scatterer and Small Baseline Approaches.” Geophysical Research Letters 35, no. 16 (August 19, 2008). doi:10.1029/2008GL034654.

Ozdemir, A. 2015. Sinkhole Susceptibility Mapping Using a Frequency Ratio Method and GIS Technology Near Karapınar, Konya-Turkey, Procedia Earth and Planetary Science, World Multidisciplinary Earth Sciences Symposium, WMESS 2015, Procedia Earth and Planetary Science, 15, 502-506.

Perissin, D., Wang, Z. and Wang, T., 2011. "The SARPROZ InSAR Tool for Urban Subsidence/manmade Structure Stability Monitoring in China.” In Proceedings of 34th International Symposium on Remote Sensing of Environment. Sydney, Australia, 2011. http://www.isprs.org/proceedings/2011/isrse34/211104015Final00632.pdf.

Ustun, A., Tusat, E., and Yalvac, S., 2010. Preliminary results of land subsidence monitoring project in Konya Closed Basin between 2006-2009 by means of GNSS observations. Natural Hazards and Earth System Science, 10(6):1151-1157.

Üstün A., Tusat E., Yalvaç S., Özkan A., Bildirici

M., Doganalp S., Canaslan F., Abbak R. A., Avsar N.B., , Eren Y., Özdemir

.Ö., Üstüntas T., Kirtiloglu O.S., Mesutoglu $\mathrm{S}$ subsidedenEFin 20drydy Gathdsed Basin and its spatio-temporal detection by GPS and DInSAR, Environmental Earth Scences, , DOI: 10.1007/s12665-0143890-5

Üstün A., Tusat E., Yalvaç S., Özkan A., Bildirici techniques and investigation of its causes, Tubitak Project Grant Number: 110Y121. 